\title{
A Case of Cochlear Implantation in Neurofibromatosis Type II
}

\author{
Se-Joon Oh, Ji-Hwan Park, Keun-Ik Yi, and Eui-Kyung Goh \\ Department of Otorhinolaryngology-Head and Neck Surgery, Pusan National University School of Medicine \\ and Medical Research Institute, Busan, Korea
}

\section{제2형 신경섬유종증 환자에서 시행한 인공와우이식}

오세준 · 박지환 · 이근익 · 고의경

부산대학교 의학전문대학원 이비인후과학교실

\author{
Received November 16, 2014 \\ Revised January 13, 2015 \\ Accepted January 22, 2015 \\ Address for correspondence \\ Eui-Kyung Goh, MD \\ Department of Otorhinolaryngology- \\ Head and Neck Surgery, \\ Pusan National University \\ School of Medicine and Medical \\ Research Institute, \\ 179 Gudeok-ro, Seo-gu, \\ Busan 602-739, Korea \\ Tel $+82-51-240-7335$ \\ Fax $+82-51-246-8668$ \\ E-mail gohek@pusan.ac.kr
}

Patients with neurofibromatosis type 2 (NF2) develop bilateral vestibular schwannomas that can cause binaural progressive hearing loss in most individuals. Auditory rehabilitation for bilateral profound sensorineural hearing loss in patients with NF2 poses a great therapeutic challenge. An auditory brainstem implantation may be an option after tumor excision, but its hearing results are still relatively unsatisfactory. A cochlear implantation (CI) may be another option in those cases where the cochlear nerve has been left intact after tumor excision or in those cases that have been kept stable after treating with Gamma-Knife. Here we report a case of undergoing CI after having been treated with Gamma-Knife in NF2 and showing improved open-set speech perception.

Korean J Otorhinolaryngol-Head Neck Surg 2015;58(7):509-13

Key Words Cochlear implantation · Gamma Knife radiosurgery · Neurofibromatosis 2.

\section{서 론}

제2형 신경섬유종증(neurofibromatosis type II, NF2)은 양측 청신경종양을 포함하는 중추신경계의 다발성 종양을 특 징으로 하는 상염색체 우성인 유전성 질환이다.) NF2 환자의 90 95\%에서 양측의 청신경종양이 발현되며, 비록 양성 종양이 지만 청각과 전정신경계에 중대한 영향을 미쳐 전농에 이르기 도 한다.) 대부분의 NF2 환자에서 양측의 청력저하가 발생하 지만, 그 경과는 예측할 수 없으며, 청각 재활은 아직 쉽지 않 고 치료에 대해서도 여전히 논란이 있다. ${ }^{3)}$ 일부에서는 양측성 청신경종양이 있을 경우 수술을 하여 종양을 제거한 후 청성 뇌간이식술(auditory brainstem implantation, $\mathrm{ABI}$ )을 시행할 것을 권유하고 있다. ${ }^{4)}$ 하지만 $\mathrm{ABI}$ 는 아직 보기 없는 조건의 말지각력(open-set speech perception)이 떨어지는 것으로 알 려져 있다. ${ }^{5)}$ 종양제거 후 청신경이 보존되었거나 감마나이프
치료를 시행한 경우에는 인공와우이식술(cochlear implantation, CI)도 하나의 선택이 될 수 있다. 그리고 CI가 아직 보기 없는 조건의 말지각력이 더 우수하고 수술위험성과 합병증, 수술시간에서 상대적으로 환자에게 더 좋은 결과를 보인다는 점에서 $\mathrm{ABI}$ 보다 우수하다는 견해도 있다. ${ }^{6}$ 저자들은 NF2 환 자의 청신경 종양에 대해 감마나이프를 시행하고, 종양의 크 기가 감소하고 안정화된 후 $\mathrm{CI}$ 를 시행하여 만족할 만한 청력 향상을 경험하였기에 이에 대해 보고하고자 한다.

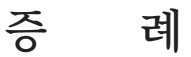

49세 남자 환자로 15 년 전부터 수개월 이상 점진적으로 양 측 귀의 청력이 악화되었고, 12 년 전 양측 청신경종양이 발견되 었다. 환자의 어머니는 양측전농인 가족력이 있었다. 그래서 유 전에 의한 NF2로 진단받고 감마나이프를 시행한 후 크기가 


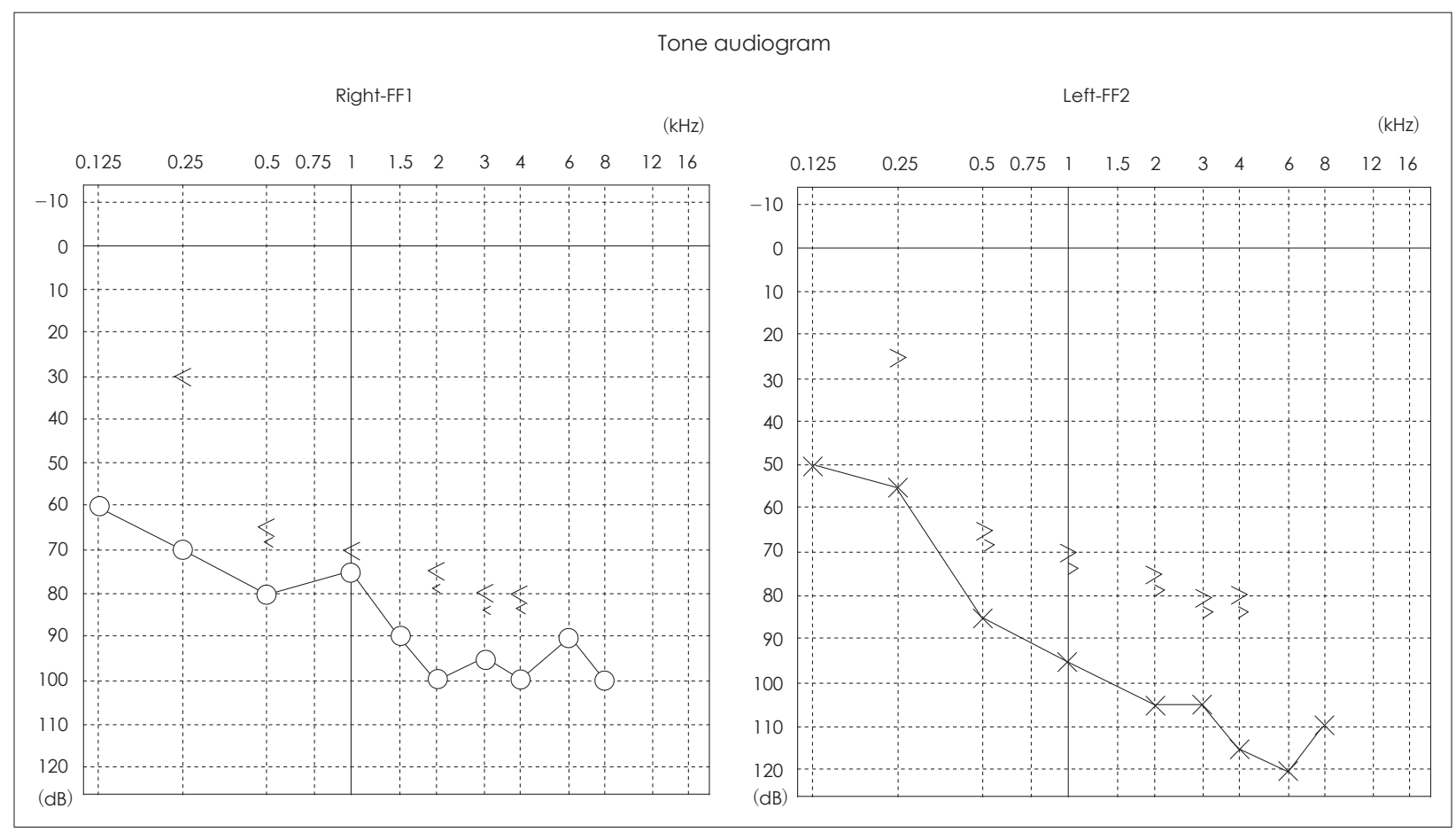

Fig. 1. Preoperative pure tone audiometry shows bilateral profound sensorineural hearing loss.

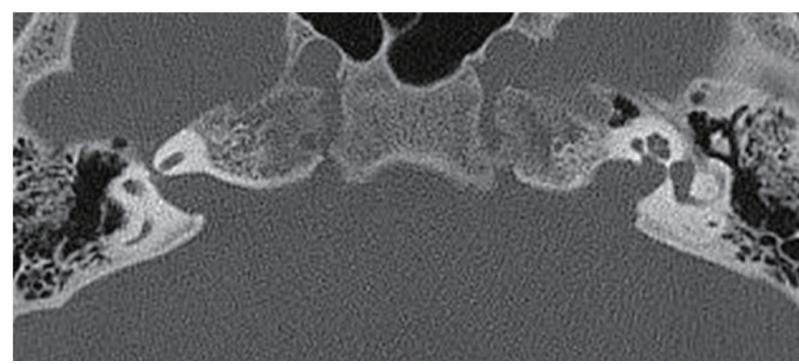

Fig. 2. Axial view of temporal bone CT shows widening of both internal auditory canals.

줄어든 상태로, 12년째 종양이 더 커지지 않고 안정적으로 경 과관찰 중이었지만 저하된 청력에 대해 평가를 위해 내원하 였다. 환자는 청신경종양 진단 1년 전 후복막종물이 발견되 어 비뇨기과에서 제거술을 받았으며, 조직검사상 신경절신경 종(ganglioneuroma)으로 진단되었었다.

순음청력검사에서 우측 귀에서 약 $88 \mathrm{~dB} \mathrm{HL}$, 좌측 귀에서 $100 \mathrm{~dB}$ HL 의 역치를 나타내었다(Fig. 1). 고실도검사는 양측 모두 A형이었고, 어음명료도는 우측 $32 \%$, 좌측 $4 \%$ 였다. 청성 뇌간유발반응(auditory brainstem response)에서 우측에서는 $90 \mathrm{~dB}$ 음자극에서 반응이 나타났고, 좌측에서는 반응이 나타 나지 않았다. 전정기능검사에서는 회전의자검사와 온도안진검 사에서 양측 전정기능 완전소실을 보였다. Hearing in noise test(HINT)에 사용된 문장을 이용한 어음분별점수는 $36 \%$ 였 고, categories of auditory performance(CAP) 점수상 3점이
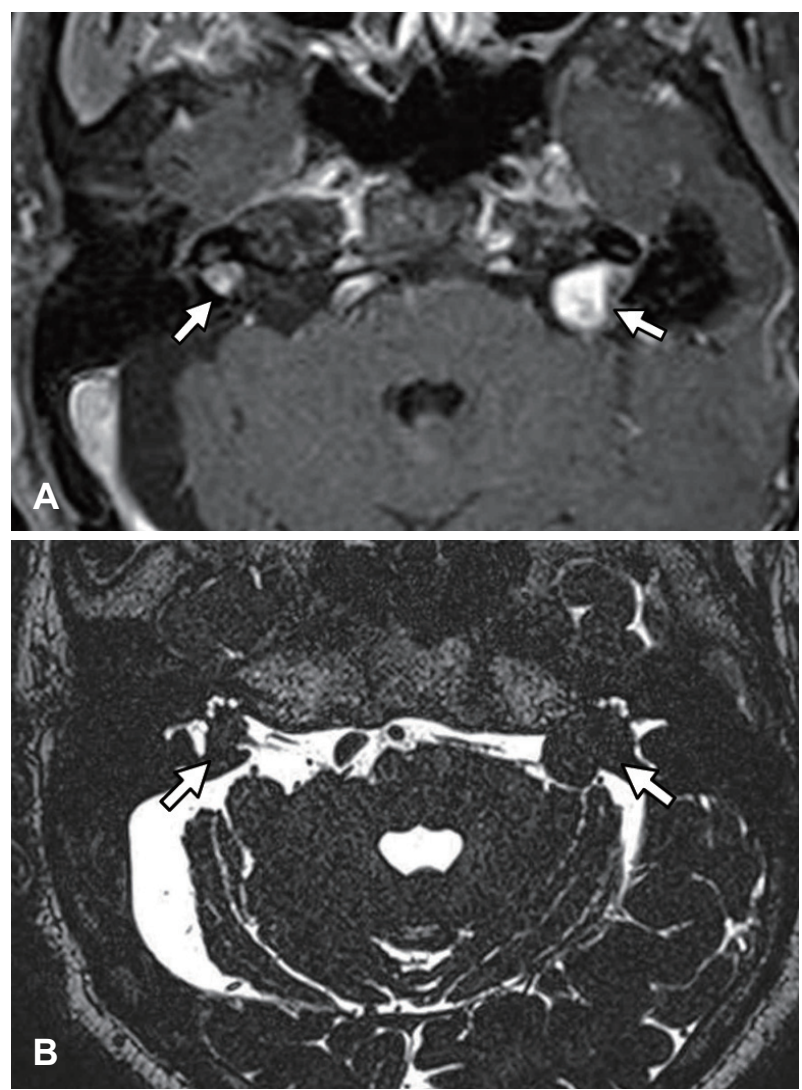

Fig. 3. MRI Axial T1-weight enhanced fat-suppression image (A). MRI Axial T2-weight 3D SPACE isotropic image (B). Both images show bilateral acoustic tumors (arrows), which its size were right $7 \times 3 \mathrm{~mm}$, left $16 \times 9 \mathrm{~mm}$. 


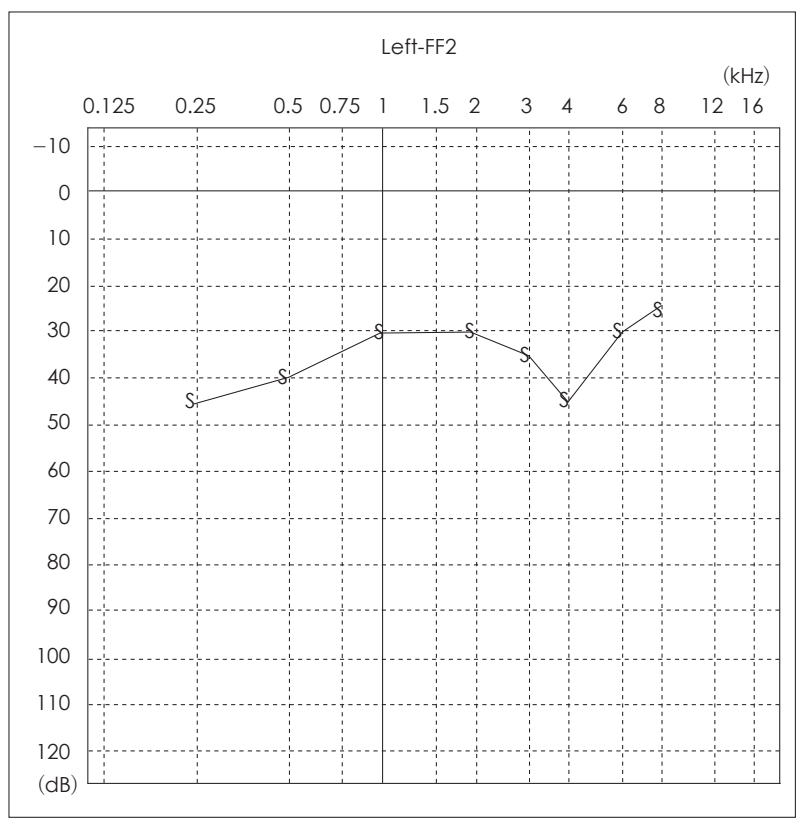

Fig. 4. Postoperative sound field audiometry.

었다. 측두골 전산화단층촬영에서는 양측 내이도의 확장을 관찰할 수 있었으며(Fig. 2), 측두 자기공명영상촬영에서는 우 측은 내이도에 국한되고, 좌측에는 내이도와 소뇌교각에 걸 친 종괴가 $\mathrm{T} 1$ 강조영상에서 관찰되었으며, 조영제에 의하여 조 영증강이 되었고 $\mathrm{T} 2$ 강조영상에서도 뇌척수액의 음영 결손이 관찰되었다(Fig. 3). 양측 청신경종은 5년 전 자기공명영상과 비 교했을 때 크기가 증가하지 않았다.

$\mathrm{CI}$ 를 시행하기로 하고, 시행 전 와우갑각전기자극검사(promontory stimulation test)를 시행하여 양이에서 비슷한 반응 역치와 gap detection을 보였다. 수술 위치에 대해서 환자와 상의한 결과 환자는 보청기를 통해 소리에 대한 반응이 남아 있는 우측의 청력은 유지하고 싶어 하여 양이청취를 위해 종 양의 크기가 더 크고 어음명료도가 더 낮은 좌측에 시행하기 로 하였다. 다만 환자에게 현재는 종양이 안정적이지만 추후 종양이 다시 자란다면 청취능력이 악화될 수 있고, 종양이 여 전히 존재하므로 일반적인 CI보다는 결과가 떨어질 수 있다는 것을 설명하였다. 수술 중 특이 소견은 없었고, 시행한 신경반 응원격(neural response telemetry) 측정에서 모든 채널에서 반응하는 것을 확인하였다. 술 후 10 개월째 조율(mapping)이 안정화된 후 HINT에 사용된 문장을 이용한 어음분별점수 는 96\%였고, CAP 점수상 7점, 순음청력검사의 음장검사 (sound field)에서는 $32 \mathrm{dBA}$ 를 보였다(Fig. 4).

\section{고 찰}

내이도 및 소뇌교각에서 발생하는 NF2에 의한 청력저하는
종양으로 인한 허혈, 경색 또는 종양의 직접적인 침범에 의해 청신경 압박과 와우 기능저하에 의한 것으로 알려져 있지만 정확한 메커니즘은 이해되지 않고 있다.) 가장 쉽게 생각할 수 있는 가설이 종양이 직접적으로 압박을 하여 청신경을 약화 시키는 것이나, 청력소실이 예측할 수 없이 발생하고 크기가 작은 종양에서도 흔히 청력소실이 발생하며 종양이 커지지 않 는데도 불구하고 점진적인 청력소실이 발생하는 점을 고려하 면 종양 크기나 성장속도와 청력저하의 단순한 관련성은 존재 하지 않을 것이라고 생각된다. ${ }^{3)}$ 뿐만 아니라 청력소실의 유형 이 점차적(progressive)이거나 단계적(stepwise), 재발성(relapsing), 완화성(remissive) 또는 갑작스럽게(sudden) 발생하는 등 양상이 다양하여 미로내 출혈, 내림프액 수종, 와우 혈류공급 의 차단, 내이액의 생화학적 환경의 변화 등이 와우 유모세포 의 퇴화 및 기능저하를 발생하는 것이 청력저하에 핵심적인 역 할을 한다.

산발성(sporadic) 또는 NF2에서의 청신경종양은 그것이 더 커지지 않는 안정적인 종양이라면 “wait and rescan"이 점점 더 선호되고 있다.") 점점 더 영상의 질이 좋아지고 조기에 진단되 며, 종양의 성장양상이 $2 / 3$ 에서는 더 성장하지 않기 때문이다. ${ }^{8)}$ 그러나 NF2에서는 양측에 종양이 존재하므로 치료방법 결정 은 더욱 복잡하다. "Wait and rescan"을 선호하는 경우도 있 고 조기에 치료하는 것이 종양이 더 작아서 제거가 용이하고 길게 봐서는 청력 유지에 유리하다는 주장이 있어 논란은 있 다. 치료를 할 때는 일반적으로 어음명료도가 더 떨어지는 쪽 의 종양을 치료한다. 그 후 반대쪽에서 청력이 저하되거나 종 양이 자란다면 치료를 하는 것이 좋으며 치료는 처음 치료를 먼저 하였던 쪽의 청력상태를 고려해야 한다.) NF2 환자들에 서 임상양상의 발현은 다양한데, 작고 안정적인 종양을 가진 상태라면 적극적인 치료를 필요로 하지 않는다. 그러나 종양 이 크고 두개 내 또 다른 종양이 있으며 다른 질병까지 동반 한다면 청력뿐 아니라 시각 등 다른 감각기능 또한 저하되어 있는 경우가 있어 적극적인 치료가 필요하다. 여러 문헌에서 는 NF2의 진단 시 나이와 증상 발현 시의 나이가 이 질환의 진행의 가장 중요한 예측인자로 보고하고 있다. ${ }^{1)}$

$\mathrm{NF} 2$ 환자에서 청각 재활은 삶의 질을 유지하기 위해 필수 적이다. 잔존청력이 많이 남아 있다면 보청기만으로도 충분 히 가능하겠지만 고도 난청이 있거나 치료 후 예상된다면 CI 혹은 $\mathrm{ABI}$ 가 최선이다. $\mathrm{CI}$ 혹은 $\mathrm{ABI}$ 를 선택하는 경우는, 종 양의 크기, 종양의 성장률, 청력, 청신경의 존재 및 기능 유 무, 환자의 선택까지 많은 것을 고려해야 한다.

$\mathrm{CI}$ 가 유리한 경우를 정리하면 첫째, 종양 절제술을 시행한 다면 청신경종양 제거 후 청신경의 보존이 가능할 것이라고 생각되는 경우이다. 둘째, 양측 고도 난청을 가지면서 종양 
절제를 계획하지 않거나 감마나이프를 받았다면 양측에서 중간 크기 이하의 안정적인 종양, 이전의 반대측에 종양 절제 술을 받고 청신경이 소실된 안정적인 편측 종양, 이전의 종양 수술 시에 청력이 보존된 경우이다.

$\mathrm{ABI}$ 가 더 유리한 경우는 종양 절제술이 계획될 때, 첫째, 반대측에도 종양이 존재하면서 수술 중 청신경 보존이 가능 하지 않거나 청신경을 보존했더라도 수술 중 전기자극 복합 활동전위(electrically evoked compound action potential)와 전기자극뇌간반응(electrically evoked brainstem response) 의 반응이 좋지 않을 때, 둘째, 반대측 종양은 절제하였는데 그쪽에서 시행한 $\mathrm{CI}$ 또는 $\mathrm{ABI}$ 의 성능이 떨어지거나 반대측 의 청력이 전혀 없는 경우이다.

결론적으로 $\mathrm{CI}$ 는 양측의 청력이 없으면서 감마나이프 치 료 이후 종양의 크기가 증가하지 않고 안정적으로 유지되는 경우 가장 효과적인 청각 재활 방법이다. 종양을 완전히 절제 하면서 청신경을 보존할 수 있는 경우에도 마찬가지이다. 예 를 들면, 경미로접근법(translabyrinthine approach)으로 종 양을 제거하면서 청신경을 보존하여 $\mathrm{CI}$ 를 동시에 시행하는 방법도 그런 예라고 할 수 있다.10) 이번 증례에서도 이런 방법 도 고려되었지만 환자는 술 후 합병증 가능성에 대해서 설명 을 듣고 현재는 종양이 안정화되어 있어 종양에 대해서는 추 가 치료를 원하지 않아 배제되었다. 청각 재활에 있어 $\mathrm{CI}$ 와 $\mathrm{ABI}$ 는 환자 수와 결과기준이 다르고 보고된 증례도 적어서 직접적으로 비교하기에는 쉽지 않다. 그럼에도 불구하고 일반 적으로 $\mathrm{CI}$ 를 시행했을 때 $\mathrm{ABI}$ 보다 더 우수한 언어지각력을 갖는 것으로 생각되는데, 청신경이 작용하는 한 소리의 전기 적 자극이 청각로로 정확하게 전달되기 때문이다. ${ }^{6,11)} \mathrm{Vin}-$ centi 등은 $\mathrm{NF} 2$ 환자에서 $\mathrm{CI}$ 를 시행할 경우와 $\mathrm{ABI}$ 를 시행 하였을 경우에 대한 비교연구를 했는데, 보기 없는 조건의 말 지각력이 $\mathrm{CI}$ 군에서는 $60 \%, \mathrm{ABI}$ 군에서는 $29 \%$ 를 보여 통계 학적으로 의미 있는 차이가 있었는데, 그 원인으로 청신경로 인 청신경과 청신경핵(cochlear neuclei)의 감수성에 대한 병 리현상과 $\mathrm{ABI}$ 기기의 전극 수 및 자극시키는 전략(stragegy) 등 의 기기의 성상 등이 $\mathrm{ABI}$ 의 결과에 영향을 미친 것으로 분석 하였다. 그리고 Sanna 등 ${ }^{12}$ 은 $\mathrm{ABI}$ 의 결과가 너무 다양하고 CI 에 비해 떨어지는 원인을 $\mathrm{ABI}$ 가 뇌간의 청신경핵이 아닌 다른 신경핵을 자극하거나 전극이 기능을 하지 못하는 등 implant 와 관련된 원인과 수술적 원인으로 전극의 위치가 옮겨지거나 탈출될 수 있는 것으로 보고하였다. 이렇게 CI가 청각학적으 로 더 우수하기 때문에 종양절제술을 하더라도 수술 중 가능 하다면 청신경을 보존하는 것이 더욱 강조되고 있다.

또한 청각학적인 장점 외에도 낮은 수술위험성, $\mathrm{CI}$ 를 먼저 시행했지만 청각신경기능 저하 등으로 추후 $\mathrm{ABI}$ 가 필요하다
면 언제든지 시행할 수 있다는 것도 $\mathrm{CI}$ 의 상대적인 우수성으 로 생각할 수 있다.

저자들은 $\mathrm{CI}$ 를 시행하기 전 술전 검사로서 와우갑각전기자 극검사를 시행하여 청신경기능을 검사하였지만 $\mathrm{CI}$ 를 위해 반 드시 양성반응이 필요한 것은 아니다. 여러 문헌에서 와우갑 각전기자극검사에서 반응이 없더라도 $\mathrm{CI}$ 를 할 수 없는 것이 아니며, 실제로 성공하였던 증례가 보고된 바 있다. ${ }^{13)}$ 그러나 청신경이 반응을 보이더라도 NF2 환자에서는 종종 청신경의 기능저하를 경험할 수 있고, 수술 중 청신경을 구조적으로 보 존할지라도 반드시 기능적이지는 않다는 점에서 일반인들에 서 시행한 CI 환자들이 경험하는 청력수준만큼의 언어지각력 을 달성하기는 쉽지 않을 것으로 보인다. ${ }^{14-16)}$

무엇보다 가장 중요한 것은 치료 후 청력 결과이다. 청신경 종에서 시행한 CI의 결과는 다양한 것으로 알려져 있으며, 본 증례에서는 보기가 없는 말소리 지각력을 달성할 수 있었으나, 그것이 가능하지 않을 수도 있다는 것을 반드시 인지해야 한 다. 그렇지만 보기가 없는 말소리 지각력을 달성할 수 없을지 라도 주변 환경음 인지나 의사소통에서 호전을 보였고, 시각 정보를 함께 이용할 때 더 많은 도움을 얻을 수 있다고 보고 된 바 있다. 다른 연구에서 $\mathrm{NF} 2$ 에서 $\mathrm{CI}$ 를 시행한 군을 보면, Pai 등근 은 NF2 환자 5명에서 CI를 시행하여 Bench-Kowal-Bamford 문장인지도검사와 City University of New York 문장검 사를 시행하여 3명에서 각각 78/93\%, 63/94\%, 89/94\% 등을 나타내어 보기가 없는 말소리 지각력이 가능하였으나 다른 한 명은 환경음 지각에서만 의미 있는 상승을, 나머지 한 명 은 와우갑각전기자극검사상 반응을 보이지 않았고 소리에 대 해 전혀 반응을 보이지 못했다고 보고하였다. NF2 또는 산발 성 청신경종 환자의 청각 재활에 대해서는 아직 논란이 많지 만, 가능하다면 $\mathrm{ABI}$ 보다는 $\mathrm{CI}$ 를 시행하는 것을 고려하는 것으 로 합의(consensus)가 모이고 있으며, 본 논문은 하나의 증례 만을 대상으로 하였지만, $\mathrm{CI}$ 를 통해 좋은 청각학적 결과를 도 출할 수 있었으며 이를 문헌고찰과 함께 보고하는 바이다.

\section{Acknowledgments}

This work was supported by clinical research grant from Pusan National University Hospital 2015.

\section{REFERENCES}

1) Kang JW, Shin JW, Lee WS, Lee HK. Decompression of internal auditory canal via middle fossa approach in neurofibromatosis type II with only hearing ear. Korean J Otolaryngol-Head Neck Surg 2006; 49(4):439-42.

2) Evans DG, Huson SM, Donnai D, Neary W, Blair V, Newton V, et al. A clinical study of type 2 neurofibromatosis. Q J Med 1992;84(304): 603-18.

3) Fong B, Barkhoudarian G, Pezeshkian P, Parsa AT, Gopen Q, Yang I. The molecular biology and novel treatments of vestibular schwannomas. 
J Neurosurg 2011;115(5):906-14.

4) Schwartz MS, Otto SR, Brackmann DE, Hitselberger WE, Shannon RV. Use of a multichannel auditory brainstem implant for neurofibromatosis type 2. Stereotact Funct Neurosurg 2003;81(1-4): $110-4$.

5) Mukherjee P, Ramsden JD, Donnelly N, Axon P, Saeed S, Fagan P, et al. Cochlear implants to treat deafness caused by vestibular schwannomas. Otol Neurotol 2013;34(7):1291-8.

6) Vincenti V, Pasanisi E, Guida M, Di Trapani G, Sanna M. Hearing rehabilitation in neurofibromatosis type 2 patients: cochlear versus auditory brainstem implantation. Audiol Neurootol 2008;13(4):273-80.

7) Tysome JR, Axon PR, Donnelly NP, Evans DG, Ferner RE, O'Connor $\mathrm{AF}$, et al. English consensus protocol evaluating candidacy for auditory brainstem and cochlear implantation in neurofibromatosis type 2. Otol Neurotol 2013;34(9):1743-7.

8) Suryanarayanan R, Ramsden RT, Saeed SR, Aggarwal R, King AT, Rutherford SA, et al. Vestibular schwannoma: role of conservative management. J Laryngol Otol 2010;124(3):251-7.

9) Trotter MI, Briggs RJ. Cochlear implantation in neurofibromatosis type 2 after radiation therapy. Otol Neurotol 2010;31(2):216-9.

10) Arístegui M, Denia A. Simultaneous cochlear implantation and translabyrinthine removal of vestibular schwannoma in an only hearing ear: report of two cases (neurofibromatosis type 2 and unilateral vestibular schwannoma). Otol Neurotol 2005;26(2):205-10.

11) Shepard TH, Tucci DL, Grant GA, Kaylie DM. Management of hearing in pediatric NF2. Otol Neurotol 2012;33(6):1066-70.

12) Sanna M, Di Lella F, Guida M, Merkus P. Auditory brainstem implants in NF2 patients: results and review of the literature. Otol Neurotol 2012;33(2):154-64

13) Pai I, Dhar V, Kelleher C, Nunn T, Connor S, Jiang D, et al. Cochlear implantation in patients with vestibular schwannoma: a single United Kingdom center experience. Laryngoscope 2013;123(8):2019-23.

14) Carlson ML, Breen JT, Driscoll CL, Link MJ, Neff BA, Gifford RH, et al. Cochlear implantation in patients with neurofibromatosis type 2: variables affecting auditory performance. Otol Neurotol 2012;33(5): 853-62.

15) Roehm PC, Mallen-St Clair J, Jethanamest D, Golfinos JG, Shapiro $\mathrm{W}$, Waltzman S, et al. Auditory rehabilitation of patients with neurofibromatosis Type 2 by using cochlear implants. J Neurosurg 2011;115(4):827-34.

16) Tran Ba Huy P, Kania R, Frachet B, Poncet C, Legac MS. Auditory rehabilitation with cochlear implantation in patients with neurofibromatosis type 2. Acta Otolaryngol 2009;129(9):971-5. 